\title{
Ruptura do ligamento cruzado cranial em um gato. Reconstituição com fáscia lata
}

\author{
Cranial cruciate ligament rupture in a cat. Reconstitution with fascia lata
}

\author{
Érika Fernanda Villamayor Garcia ${ }^{*}{ }^{*}$ João Eduardo Wallau Schossler ${ }^{I I}$ Maicon Pinheiro ${ }^{\mathrm{I}}$
}

\begin{abstract}
Em gatos, a ruptura do ligamento cruzado cranial RESUMO (RLCC) trata-se de diagnóstico raro e a correção cirúrgica propicia o retorno mais rápido à função do membro. Foi atendida, no Hospital Veterinário da Universidade Federal de Santa Maria (UFSM), uma gata apresentando claudicação aguda e dor à palpação do joelho direito. O diagnóstico de RLCC foi realizado através dos testes de compressão tibial e gaveta cranial positivos e confirmado na cirurgia. Optou-se por realizar a reconstituição do ligamento com fáscia lata e, após achados clínicos pós-operatórios e em longo prazo concluiu-se que a técnica apresentou resultados satisfatórios neste caso.
\end{abstract}

Palavras-chave: gato, joelho, fáscia lata.

\section{ABSTRACT}

The cranial cruciate ligament rupture (CCLR) is rare diagnosis in cats and the surgical correction provides a faster return to limb function. A cat with acute lameness and pain on palpation of the right stifle was attended at the Veterinary Hospital of UFSM. The diagnosis of CCLR was performed by positive tibial compression test and positive cranial drawer sign and confirmed by surgery. We chose to perform the reconstruction of the ligament with fascia lata and after of the observe clinical postoperative and in the long-term it was concluded that the technique showed satisfactory results in this case.

Key words: cat, stifle, fascia lata.

A ruptura do ligamento cruzado cranial (LCCr) em gatos ocorre menos frequentemente em relação aos cães e geralmente está acompanhada por lesões multiligamentares ou ósseas (HARASEN, 2005). A etiologia da ruptura do LCCr no gato não está esclarecida, mas parece ser uma condição multifatorial em que trauma, fatores genéticos, inflamatórios, nutricionais e imunológicos resultam em doença articular degenerativa, predispondo à ruptura do ligamento (SCHNABL et al., 2009; LASCELLES, 2010). Ainda segundo MCLAUGHLIN (2002), o ligamento cruzado cranial no gato é maior que o ligamento cruzado caudal, o que pode contribuir para este resultado; além de deformidades ósseas associada ao ângulo do platô tibial, raça, idade e peso corporal (SCHNABL et al., 2009; LASCELLES, 2010). A etiologia da ruptura do LCCr no gato é dividida em dois grupos distintos: o associado ao traumatismo devido a quedas, saltos ou atividade atlética (HARASEN, 2005) e o associado a gatos pesados, com mínimo ou nenhum traumatismo, ocorrendo, neste caso, a degeneração do ligamento, em especial naqueles animais com idade avançada e excesso de peso, os chamados "gatos indoor" (HARASEN, 2005).

Os sinais clínicos incluem claudicação repentina, dor articular, efusão intra-articular, instabilidade e eventualmente osteoartrite. Ao contrário dos cães, na ruptura do LCCr em gatos, a frouxidão articular é geralmente palpável mesmo em casos crônicos, pois a fibrose periarticular não é tão

'Programa de Pós-graduação em Medicina Veterinária, Universidade Federal de Santa Maria (UFSM), Santa Maria, RS, Basil. Email: erikavet5@hotmail.com. Autor para correspondência.

"Departamento de Clínica de Pequenos Animais, Centro de Ciênicas Rurais, UFSM, Santa Maria, RS, Brasil. 
proeminente (MCLAUGHLIN, 2002). O movimento de gaveta cranial e o teste de compressão tibial positivos são usados para confirmar a presença de instabilidade articular. A avaliação radiográfica do joelho pode revelar deslocamento cranial da tíbia, efusão articular e sinais de osteoartrite em casos mais crônicos (MCLAUGHLIN, 2002; VOSS et al. 2009).

Por apresentarem porte atlético e peso leve, o tratamento conservador em gatos tem sido sugerido nos casos de ruptura isolada do LCCr (SCAVELLI \& SCHRADER, 1987). No entanto, devido a alterações articulares degenerativas secundárias e à persistência do sinal de gaveta cranial, a estabilização cirúrgica é hoje o tratamento de escolha com resultados favoráveis emum retorno mais rápido à função do membro(HARASEN, 2005; SCHNABL et al., 2009; VOSS etal., 2009).

As técnicas cirúrgicas para a correção da ruptura do LCCr podem ser divididas em técnicas extraarticulares, intra-articulares, e osteotomias corretivas (DENNY \& BUTTERWORTH, 2006; SCHULZ, 2008). Métodos extra-articulares envolvem o uso de sutura não absorvível de grosso calibre aplicada ao redor da fabela até a crista da tíbia, restaurando a estabilidade articular externamente à articulação (SCHULZ, 2008). Os métodos intra-articulares envolvem a substituição do ligamento cruzado com enxerto autógeno ou materiais sintéticos (PIERMATTEI et al., 2009). As osteotomias corretivas restauram a estabilidade pela alteração da geometria e biomecânica articular (KIM et al., 2008; VOSS et al., 2009).

Paatsama na década de 50 desenvolveu uma das primeiras técnicas intra-articulares utilizando um retalho de fáscia lata para substituir o LCCr. Desde então, vários métodos têm sido desenvolvidos (PIERMATTEI et al., 2009). IAMAGUTI et al. (1998), utilizando a técnica modificada, constataram que esta pode ser indicada em casos tais como ruptura total ou parcial, crônica ou aguda, em cães de pequeno e grande porte, ativos ou não, jovens ou idosos e tanto para ruptura do ligamento cruzado cranial como caudal. O objetivo deste trabalho é descrever a utilização da técnica modificada de reconstituição do ligamento cruzado cranial com fáscia lata em um gato.

Foi atendida no Hospital Veterinário da UFSM uma gata sem raça definida, de dois anos de idade, pesando $4 \mathrm{~kg}$, apresentando claudicação aguda e dor na região do joelho do membro direito. Foi relatado que o animal havia sumido de casa havia dois dias. Ao exame físico, o paciente apresentava apoio intermitente do membro em questão, aumento de volume e desconforto à palpação do joelho. Para avaliação da articulação, foi realizada sedação com propofol (4mg $\mathrm{kg}^{-1}, \mathrm{IV}$ ), e se constatou movimento de gaveta cranial em extensão e teste de compressão tibial positivos. Após a realização de exames pré-operatórios, o animal foi encaminhado para correção cirúrgica, através da técnica de retalho pediculado de fáscia lata, seguindo a técnica de Paatsama, com modificação descrita na sequência.

Ao realizar artrotomia parapatelar lateral, a articulação do joelho foi inspecionada, os meniscos apresentavam-se íntegros e o LCCr remanescente foi removido (Figura1-A). Em seguida, com broca de 3mm, realizou-se perfuração desde a fossa intercondilar até um ponto proximal no epicôndilo lateral do fêmur (Figura1-B). Retirou-se um retalho pediculado de fáscia lata de aproximadamente $1,0 \mathrm{~cm}$ de largura através de duas incisões paralelas estendendo-se desde o trocanter maior até o epicôndilo lateral do fêmur (Figura1-C), mantendo-se pediculado neste ponto (Figura 1-D). Após, com auxílio de guia de fio de aço, o retalho foi passado através do orifício até a fossa intercondilar (Figura 1-D). Realizou-se então orifício desde a iminência intercondilar até a face medial da extremidade proximal da tíbia (Figura1-E). Após a passagem do retalho de fáscia lata pelo orifício criado (Figura 1-F), esta foi suturada sobre as fáscias musculares da face medial proximal da tíbia com padrão de sutura Wolff, com fio de náilon monofilamentar 3-0. A fáscia lata remanescente foi suturada em padrão contínuo simples utilizando fio de ácido poliglicólico 3-0. A sutura da cápsula articular foi obtida em Wolff com fio de náilon monofilamentar 3-0, a abolição do espaço morto com pontos contínuo simples com fio de ácido poliglicólico 3-0 e os pontos de pele em padrão Wolff com fio de náilon monofilamentar 3-0. Aplicouse curativo com micropore ao redor do joelho visando a colaborar com a restrição do movimento articular. $\mathrm{O}$ paciente foi mantido em espaço restrito durante três dias e, após esse período, o curativo foi retirado e repouso foi recomendado. Uma semana após a cirurgia, o paciente começou a apoiar o membro levemente. Aos 20, dias este apresentou apoio normal do membro operado, inclusive subindo em árvores, pulando básculas e somente claudicando esporadicamente, segundo relato do proprietário.

O paciente foi reavaliado dois anos após a cirurgia e, nesta ocasião, observou-se ganho de peso de $900 \mathrm{~g}$. Apresentava deambulação normal e leve espessamento da articulação do joelho operado, porém sem movimento de gaveta ou sinal de instabilidade articular. Foi observada diminuição leve da amplitude de movimento da articulação operada em relação ao membro contralateral, não alterando o uso fisiológico do membro. 


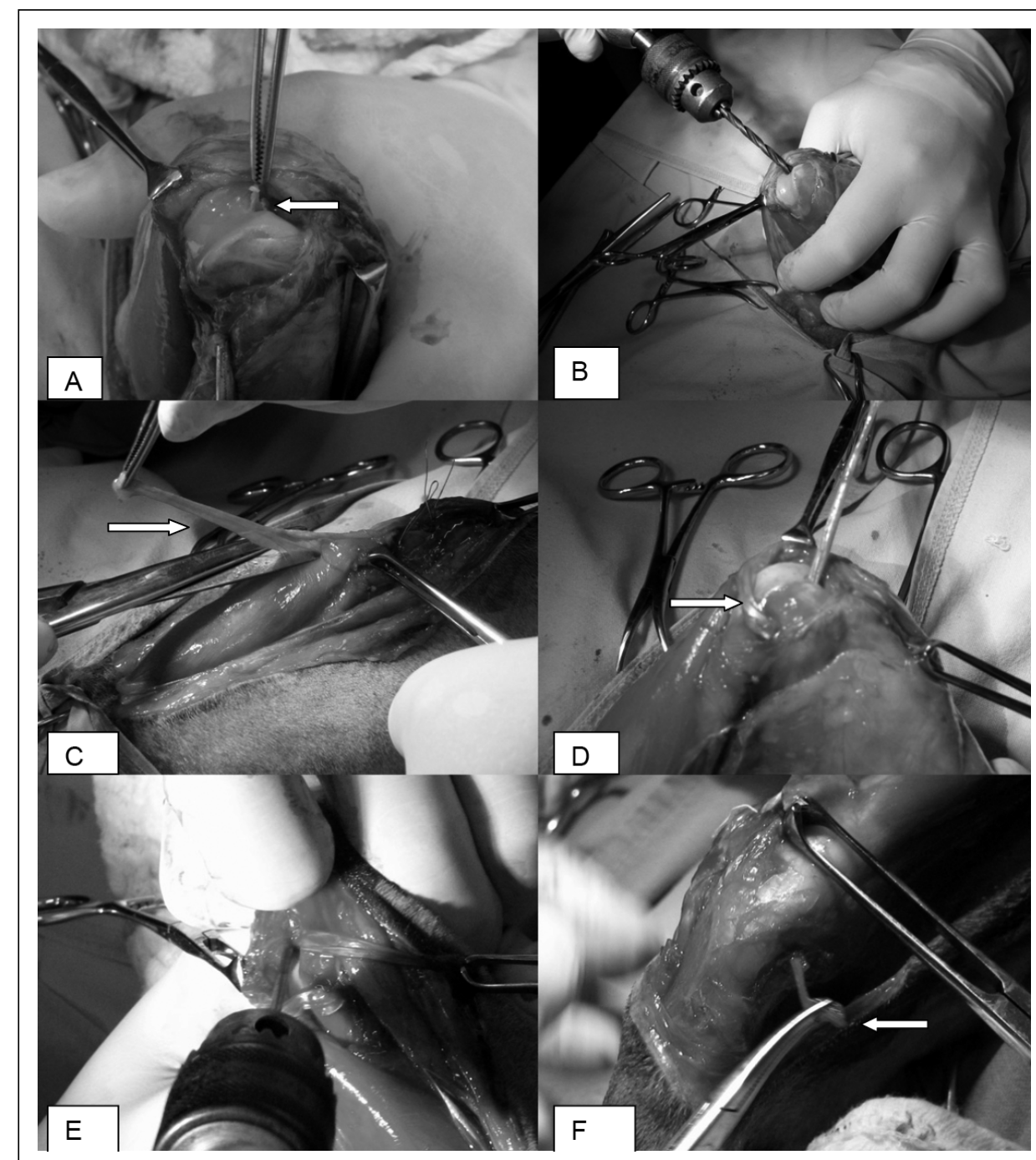

Figura 1 - Felino, sem raça definida, fêmea, 2 anos, submetido à reconstrução do ligamento cruzado cranial. A - visualização do LCCr remanescente (seta); B - perfuração desde a fossa intercondilar até o epicôndilo lateral do fêmur; C - retalho pediculado de fáscia lata (seta) seccionado desde o trocanter maior até o epicôndilo lateral do fêmur; D - retalho pediculado de fáscia lata a partir do epicôndilo lateral do fêmur (seta) após passagem pelo orifício criado anteriormente, emergindo na fossa intercondilar; E - perfuração desde a iminência intercondilar até a face medial da extremidade proximal da tíbia; F - retalho de fáscia lata já na face medial da região proximal da tíbia (seta).

Embora a ruptura do LCCr seja uma afecção comum em cães e com vasta descrição na literatura científica, pouca atenção tem sido dada a esse tipo de alteração em gatos. É provável que esta incidência esteja subestimada, pois, ao contrário dos cães, muitos gatos se recuperam da claudicação dos membros pélvicos sem tratamento, podendo não ser examinados (HARASEN, 2005). O fato de o paciente apresentar claudicação aguda e o bom senso do proprietário em trazê-lo para consulta rapidamente propiciou diagnóstico preciso e tratamento eficaz. Considerando a idade do paciente e histórico, suspeita-se de que a ruptura do LCCr tenha sido de origem traumática e, apesar dessa hipótese, não foi observado nenhum dano a outras estruturas do joelho, condição comumente observada nos casos associados a trauma maior (HARASEN, 2005).

A cirurgia foi o tratamento de escolha principalmente por propiciar o retorno rápido à função do membro. SCAVELLI \& SCHRADER (1987) 
demonstraram que com tratamento conservador os animais apresentaram-se livres de dor, marcha e amplitude de movimento do joelho normal, porém para melhores resultados o animal deve ser de fácil contenção (em quarto ou gaiola) e de peso leve. O paciente do presente relato era recém castrado, com possibilidade de ganho de peso, o que foi observado após dois anos. Este fato poderia comprometer o tratamento conservador, já que o peso corporal é um fator importante para o resultado satisfatório.

Estudos prospectivos têm mostrado índice de êxito próximo a $90 \%$, independentemente da técnica de reconstrução escolhida (SCHULZ, 2008). Em gatos, a sutura fabelo-tibial lateral é a preferida pela maioria dos cirurgiões (MCLAUGHLIN, 2002; SCHULZ, 2008; VOSS et al., 2009). No entanto, algumas complicações como deslocamento do fio da posição ao redor da fabela lateral, excesso de tensão da sutura e afrouxamento do fio podem ser observadas (POZZI, 2010). No animal em questão, optou-se pela modificação da técnica intraarticular com fáscia lata, pois, diferentemente da técnica original de Paatsama, mantendo-se o flape pediculado lateralmente, aumenta-se a tensão do ligamento patelar e consequentemente estabilidade articular. Segundo SCHULZ (2008) e PIERMATTEI et al. (2009), a técnica intra-articular tem como vantagem mimetizar com maior perfeição a posição original e a biologia do LCCr original. Complicações como ruptura e afrouxamento do enxerto também podem ocorrer, contudo a incidência é baixa (BRENDOLAN et al., 2001). Não foi observada nenhuma das alterações descritas acima no presente relato.

O espessamento periarticular e a diminuição da amplitude articular do joelho operado são alterações comuns neste tipo de cirurgia. Os procedimentos cirúrgicos intra e extra-articulares objetivam a reconstrução das contenções passivas da articulação do joelho (LCCr e fibrose da cápsula articular), portanto, não importa a técnica usada, sempre é a fibrose periarticular que vai estabilizar a articulação (DENNY \& BUTTERWORTH, 2006; SCHULZ, 2008). O retorno à função do joelho operado foi rápido, ao redor dos 20 dias, concordando com os achados de IAMAGUTI et al. (1998), que relata início de apoio a partir de cinco dias pós-operatório e retorno à função em até 30 dias após a cirurgia.

Com base nos achados clínicos do pósoperatório imediato e em longo prazo, pode-se concluir que a técnica modificada para a reconstituição do ligamento cruzado cranial com fáscia lata foi eficiente neste caso.

\section{REFERÊNCIAS}

BRENDOLAN, A.P. et al. Propriedades biomecânicas da fáscia lata e do ligamento cruzado cranial de cães. Arquivo Brasileiro de Medicina Veterinária e Zootecnia, v.53, n.1, p.27-36, 2001. Disponivel em: <http://www.scielo.br/scielo.php?pid=S010209352001000100005\&script=sci_arttext $>$ Acesso em: 18 maio, 2011. dói 10.1590/S0102-09352001000100005.

DENNY, H.R.; BUTTERWORTH, S.J. Cirurgia ortopédica em cães e gatos. 4.ed. São Paulo: Roca, 2006. 496p.

HARASEN, G.L.G. Feline cranial cruciate rupture. 17 cases and a review of the literature. Veterinary and Comparative Orthopaedics and Traumatology, v.18, n.4, p.254-257, 2005.

IAMAGUTI, P. et al. Ruptura do ligamento cruzado em cães. Estudo retrospectivo da reconstituição com fascia lata. Ciência Rural, v.28, n.4, p.609-615, 1998.

KIM, S.E. et al. Tibial osteotomies for cranial cruciate ligament insufficiency in dogs. Veterinary Surgery, v.37, n.2, p.111125, 2008.

LASCELLES, B.D.X Feline degenerative joint disease. Veterinary Surgery, v.39, n.01, p.02-13, 2010.

MCLAUGHLIN, R.M. Surgical diseases of the feline stifle joint. Veterinary Clinics of North America: Small Animal Practice, v.32, n.4, p.963-982, 2002.

PIERMATTEI, D.L. et al. Ortopedia e tratamento de fraturas de pequenos animais. 4.ed. Barueri: Manole, 2009. 934p.

POZZI, A. Pearls and pitfalls of extracapsular techniques. In: WORLD VETERINARY ORTHOPAEDIC CONGRESS, 3., 2010, Bologna (Italy). Anais... Bologna: European Society of Veterinary Orthopaedics and Traumatology, 2010. p.749.

SCAVELLI, T.D.; SCHRADER, S.C. Nonsurgical management of rupture of the cranial cruciate ligament in 18 cats. Journal of the American Animal Hospital Association, v.23, p.337340, 1987

SCHNABL, E. et al. Measurement of the tibial plateau angle in cats with and without cranial cruciate ligament rupture. Veterinary and Comparative Orthopaedics and Traumatology, v.22, n.2, p.83-86, 2009.

SCHULZ, K. Afecções articulares. In: FOSSUM, T.W. Cirurgia de pequenos animais. 3.ed. Rio de Janeiro: Elsevier, 2008. Cap. 33, p.1143-1315.

VOSS, K. et al. Stifle joint In: VOSS, K. et al. Feline Orthopedic Surgery and Musculoskeletal disease. Philadelphia: Saunders Elsevier, 2009. Cap. 38, p.475-490. 